\title{
Heightened prey responses in risky habitats: predation pressure increases prey sensitivity to predation risk
}

\author{
Delbert L. Smee ${ }^{1, *}$, Marc J. Weissburg ${ }^{2}$ \\ ${ }^{1}$ Texas A\&M University - Corpus Christi, 6300 Ocean Drive, Corpus Christi, Texas 78412, USA \\ ${ }^{2}$ Georgia Institute of Technology, School of Biology, 310 Ferst Drive, Atlanta, Georgia 30332, USA
}

\begin{abstract}
Previous studies have shown that prey living under intense consumer pressure possess stronger defenses against consumers than related species in habitats where consumer pressure is low. We tested whether prey sensitivity to risk would be heightened in habitats with elevated predation pressure and accordingly whether prey living in these areas would be more likely to initiate predator avoidance behaviors. Using the hard clam Mercenaria mercenaria as a model organism, we compared predation intensity on clams as well as their responses to predation risk from a population in Georgia to one in Maine, USA. Previous studies have shown that clams in Georgia react strongly to chemical cues from sympatric predators. In this study, we found that with the exception of starfish, clams from Maine did not react to their predators, and only responded when presented with cues from injured conspecifics. Predation was significantly greater in Georgia than in Maine, and clams from Georgia reacted more frequently and more intensely to risk than did those from Maine. The stronger responses from Georgia clams were observed when clams from both populations were assayed at the same level of risk (cue from injured conspecifics) and performed in the same environmental conditions. Our results suggest that prey sensitivity to chemical cues indicative of risk, and the intensity and frequency of responses to risk, may be related to local consumer pressure. Prey sensitivity to risk subsequently may display a geographical pattern, as predation is generally more intense in lower latitudes.
\end{abstract}

KEY WORDS: Chemical cue $\cdot$ Clam $\cdot$ Crab $\cdot$ Flume $\cdot$ Mercenaria mercenaria $\cdot$ Predator avoidance Predator-prey interaction $\cdot$ Risk evaluation

\section{INTRODUCTION}

Prey decrease their vulnerability to predators through a variety of responses (Katz \& Dill 1998) including changing their morphologies (e.g. Leonard et al. 1999, Nakaoka 2000, Relyea 2001), manufacturing new or increasing current levels of chemical defense (e.g. Hay 1996, Bolser \& Hay 1996), initiating avoidance behaviors (e.g. Lima \& Dill 1990, Schmitz et al. 1997, Trussell et al. 2003) or selecting different habitats (Turner \& Mittlebach 1990). Numerous studies have documented high costs associated with predator avoidance; most notably prey experience a net loss in growth, fecundity or both (e.g. Katz \& Dill 1998, Leonard et al. 1999, Tollrian \& Harvell 1999, Nakaoka
2000). Since predator avoidance is costly, many prey species have evolved plastic or variable responses to predation risk, and the degree to which prey respond to predators is related to the perceived level of risk (Harvell 1986, Katz \& Dill 1998, Tollrian \& Harvell 1999). Therefore, changes in prey traits in response to predation risk are often greater in habitats with intense consumer pressure and/or where predators are most prevalent (Vermeij 1978, Menge \& Lubchenco 1981, Bolser \& Hay 1996, Pennings et al. 2001).

Many studies have shown that consumer pressure exhibits a biogeographical pattern where both predation and herbivory are greater at lower latitudes (Vermeij 1978, Jeanne 1979, Bertness et al. 1981, Menge \& Lubchenco 1981, Gaines \& Lubchenco 1982, Fawcett 
1984, Heck \& Wilson 1987, Bolser \& Hay 1996, Pennings et al. 2001). Prey living in lower latitudes that experience higher levels of consumer pressure often display stronger morphological (Vermeij 1978, Bertness et al. 1981) or chemical (Coley \& Aide 1991, Bolser \& Hay 1996, Pennings et al. 2001) defenses than congeners or conspecifics living in temperate habitats where consumer pressure is lower. Like morphological and chemical defenses, behavioral responses to predators can also differ between prey populations across geographic areas that experience different predation rates (Bertness et al. 1981, Fawcett 1984).

Bertness et al. (1981) compared the foraging activity of herbivorous snails in tropical and temperate waters. In New England, snails foraged during high tide to avoid physical stress caused by exposure during low tide. In contrast, snails in Panama typically foraged during low tide, even though conditions at low tide were more stressful than those in New England. Bertness et al. (1981) attributed differences in snail foraging to predation pressure from snail-crushing fish, which are common in tropical waters and not found in New England. Thus, tropical snails elected to forage in a more stressful (exposed) environment to negate predation risk by fish.

Similarly, Fawcett (1984) compared predation intensity and habitat choice by a trochid snail, Tegula funebralis, along the coast of California and found both higher predation rates in lower latitudes and differential predator responses in habitats with low versus high predation pressure. Fawcett (1984) found that the lower limits of $T$. funebralis in the intertidal zone are higher in habitats with intense consumer pressure. $T$. funebralis migrated farther up the shore and into a less suitable habitat to reduce predation risk despite lower resource availability in the high intertidal zone. $T$. funebralis transplanted between northern and southern sites exhibited similar behaviors, and regardless of their original location, moved faster and farther up the shore in habitats where predation pressure was greater (Fawcett 1984). Fawcett (1984) attributed the greater predation rates in the south to the presence of octopuses, which were not present in northern study sites.

Since morphological, chemical, and behavioral defenses can vary between prey populations under different consumer pressure, we tested whether prey sensitivity to risk and their likelihood of initiating avoidance behaviors would be greater in habitats with more intense predation. Although Bertness et al. (1981) and Fawcett (1984) demonstrated geographical differences in predation pressure and predator avoidance responses, the increase in consumer pressure and change in prey responses between regions results from a guild of predators that are present in lower latitudes and absent in higher ones. Therefore, neither study directly addresses how predation pressure affects prey thresholds for initiating avoidance behaviors.

Using the hard clam Mercenaria mercenaria as our model organism, we compared populations in Georgia and Maine, USA, with respect to predation intensity on clams, as well as clams' predator detection and avoidance responses. Previous research has shown that clams in Georgia alter their pumping behavior in response to chemical cues released from predators and injured conspecifics (Smee \& Weissburg 2006a,b), which decreases their mortality (Smee \& Weissburg 2006a). M. mercenaria are found in the intertidal zone along the eastern North American coast from the Gulf of Mexico into the Gulf of St. Lawrence. They provide an excellent model organism for this study because they react to chemical signals emanating from injured conspecifics. Using cues from injured conspecifics allowed us to compare clam responses to the same risk cues and evaluate response differences between populations that experience significantly different predation levels. Our results indicated that predation intensity was greater in Georgia than in Maine and that Georgia clams responded more frequently and more intensely to risk than Maine conspecifics. These observations support the hypothesis that prey perception of risk and the likelihood of initiating avoidance behaviors vary with predation pressure.

\section{METHODS AND MATERIALS}

Study sites. Surveys of clam densities and measurements of predation intensity on clams were conducted in the Damariscotta River in Maine and in the Wilmington River and 2 of its tributaries (Skidaway and Herb rivers) near Wassaw Sound in Georgia. Both sites are inland estuaries with minimal wave action, lack significant freshwater input, have a large tidal range ( 2 to $4 \mathrm{~m}$ ) and are natural habitats for clams and their predators. Additionally, these field sites are relatively large, stretching for over $3 \mathrm{~km}$, and contain many microhabitats common to their respective study areas. Our field site in Georgia was bordered by marsh (containing mostly Spartina alterniflora) and is typical of other soft-sediment habitats in the southeast USA. The Damariscotta River contains both rocky intertidal and soft-sediment habitats. Clams are soft-sediment animals, and we conducted our experiments in these areas of the Damariscotta River, which are similar to other northern soft-sediment communities.

Clam density survey. During June and July of 2004, we conducted a survey of hard clam population densities in both study areas to establish a known clam density for use in our predation intensity comparison 
experiments (see next section). Clam densities were measured by placing a $1.0 \mathrm{~m}^{2}$ grid in the intertidal zone, digging for clams using rakes and fingers, and counting the total number of clams within the grid. Hard clams are commonly aggregated in the field, and we wanted to assess the density of clams found within established beds. Naturally occurring clam beds were located by haphazardly digging $0.25 \mathrm{~m}^{2}$ areas using a clam rake. Whenever a clam was found we would then place the $1.0 \mathrm{~m}^{2}$ grid over the clam and sample the surrounding area. We counted all clams within the grid and determined whether each clam was a juvenile or adult by measuring its shell length (adult clams $>30 \mathrm{~mm}$ ). A $t$-test was used to compare clam densities between Maine and Georgia sites (Sokal \& Rohlf 1995).

Comparison of predation intensity. Predation intensity on clams was measured in Georgia and Maine during July and August 2004 using a simple mark and recovery experiment. Clams collected from the field were individually tethered with monofilament line ( $0.15 \mathrm{~m}$ long) glued to the shell and tied to ropes ( $0.50 \mathrm{~m}$ long) strung between 2 lengths of PVC pipe $(0.50 \mathrm{~m}$ long $\times 0.125 \mathrm{~m}$ diameter $)$. The area of the PVCrope frame was $0.25 \mathrm{~m}^{2}$, and it provided easy transportation of clams to the field site and facilitated the eventual sampling of clam mortality by allowing us to recover both live clams and shells of clams that were eaten. Clam plots were placed in the field and recovered after $48 \mathrm{~h}$ in Georgia and $1 \mathrm{wk}$ in Maine. Preliminary data indicated that predation rarely occurred in Maine after $48 \mathrm{~h}$, and we allowed clam plots to remain in the field longer in Maine to ensure measurable predation rates. After clam plot retrieval, we recorded the status of each clam as alive, missing or eaten. Previous research has shown that missing clams are taken by crabs (Smee \& Weissburg 2006a), and we counted missing clams as being consumed in this study. Other investigators have followed a similar logic and have attributed missing clams to crustacean predators (Micheli 1997, Nakaoka 2000).

To measure predation rates in Georgia, we attached 15 clams, 10 juveniles $(<20 \mathrm{~mm})$ and 5 adults $(>35 \mathrm{~mm})$, to the rope-PVC frame and haphazardly placed them at least $100 \mathrm{~m}$ apart in the Wilmington River and associated tributaries near Savannah, Georgia. This created a clam density of 60 clams $\mathrm{m}^{-2}$ inside the plots, which was within the range of naturally occurring clam densities in Wassaw Sound (Walker 1987). We also placed plots containing 15 clams (10 juveniles and 5 adults, density 60 clams $\mathrm{m}^{-2}$ ) haphazardly in the Damariscotta River, Maine, near naturally occurring clam populations. Twenty clam plots were placed in both Georgia and Maine for this comparison. Since clam plots were left in the field for different intervals in each study area, we converted each mea- surement of predation intensity into a rate of clams eaten per day to compare results across regions. These data were arcsine transformed to meet ANOVA assumptions and compared using a $t$-test (Sokal \& Rohlf 1995).

Clam densities in Georgia were almost double those measured in Maine (see 'Results'), and using 15 clams per plot in Maine may have caused us to report higher predation rates than naturally occur in this habitat. Thus, we conducted an additional experiment to determine whether changes in clam density affected predation rates in Maine and to establish predation levels on patches that more closely resembled clam density of populations in Maine. In this experiment, we created plots with 5 clams per plot, 3 juveniles and 2 adults, creating a clam density of 20 clams $\mathrm{m}^{-2}$. This density more closely resembled the naturally occurring density of clams in Maine. We then placed them in the Damariscotta River alongside plots with 15 clams. Low and high density plots were placed $10 \mathrm{~m}$ apart and at least $100 \mathrm{~m}$ from any other pair. Ten pairs of these plots were used and remained in the field for $1 \mathrm{wk}$. We compared the number of clams found alive in the low and high density plots using a paired $t$-test (Sokal \& Rohlf 1995).

Behavioral assays. All behavioral assays were performed at the Darling Marine Center (DMC) in Walpole, Maine.

Animal capture and maintenance: Animals used in the study were collected from the Damariscotta River near the DMC. Clams were collected by digging in the intertidal zone, and clam predators including American lobsters Homarus americanus, rock crabs Cancer irroratus, Jonah crabs C. borealis, green crabs Carcinus maenas, and northern starfish Asterias forbesi were collected in the Damariscotta River using baited lobster traps and by hand using SCUBA. Animals were returned to the DMC after capture and housed in flowthrough sea tables. Clams were allowed to acclimate for at least $6 \mathrm{~h}$ prior to behavioral assays and were not used in experiments if they had remained in the sea tables for longer than $48 \mathrm{~h}$. All clam predators were fed a diet of clams ad libitum for at least $1 \mathrm{wk}$ prior to use in the behavioral assays. Each clam and predator were used only once and then returned to the field.

Blue crabs Callinectes sapidus and knobbed whelks Busycon carica, which are the primary clam predators in Georgia, were collected in Wassaw Sound. In this study, clams from Maine also were exposed to these exotic predators in behavioral assays. Blue crabs were collected with crab pots and knobbed whelks were collected by hand in the intertidal zone. After collection, blue crabs and knobbed whelks were shipped to the DMC and placed in isolated aquaria to prevent introduction of nonnative organisms into Maine waters. 
Water in these aquaria was changed daily, and both blue crabs and knobbed whelks were the fed same clam diet as local predators before use in experiments.

Hydrodynamic environment for behavioral studies: Behavioral experiments were conducted in a laboratory flume at the DMC. The flume was $2.2 \mathrm{~m}$ long, $0.53 \mathrm{~m}$ wide and had a false bottom (diameter $0.13 \mathrm{~m}$ ) located $1.4 \mathrm{~m}$ downstream, which permitted clams to burrow. Free-stream flow velocity and water depth were maintained at $3 \mathrm{~cm} \mathrm{~s}^{-1}$ and $0.10 \mathrm{~m}$, respectively, during all behavioral assays. The flume was supplied by water pumped directly from the Damariscotta River and was discharged back into the river after a single pass through the flume. Water used in trials with exotic animals was first captured in a large tank and treated with bleach prior to release in the field.

Clam reactions to predators: We examined Maine clam pumping activity in response to different predators and chemical cues during the summer of 2004. These experiments used changes in clam pumping (feeding) behavior as assays for the ability of clams to detect and respond to predation risk. Previous research using hard clams from Georgia has shown that clams are actively pumping when their siphons are extended (Smee \& Weissburg 2006a,b), and other authors have used siphon extension as an indicator of clam pumping (e.g. Irlandi \& Peterson 1991). In preliminary assays using Maine clams, we noticed that clams occasionally would close their excurrent siphon, but not retract their siphons into their shells. That is, in Maine we observed a reaction to predators not observed in Georgia whereby clams do not pump, but leave their siphons extended. Since siphon extension was not evidence of clam pumping, we verified pumping activity in clams with extended siphons by carefully pipetting dye near the excurrent siphon of each clam to visualize the excurrent released during pumping. In some cases, Maine clams would retract their siphons and completely close their shells. We measured both of these responses to risk in our assays.

Behavioral assays were conducted in the DMC flume and consisted of challenging clams to detect and respond to predators, injured conspecifics, and in some cases, combinations of these cues. We judged clam responses to predation risk by determining whether clam pumping occurred significantly less often in response to these treatments when compared with a control that lacked predators or injured conspecifics. In each assay, we placed 3 clams in the false bottom of the flume and allowed them to acclimate for $20 \mathrm{~min}$. Preliminary observations indicated that this time was sufficient for clams to burrow and begin pumping. After the 20 min acclimation period, we introduced predators, crushed conspecifics, or a combination of these cues by placing a caged predator, injured clam, or both
$0.5 \mathrm{~m}$ upstream from the clams. The predator cage was made from Vexar mesh with $1.0 \mathrm{~cm}^{2}$ openings and was cylindrical in shape with a height of $0.10 \mathrm{~m}$ and a diameter of $0.15 \mathrm{~m}$.

We recorded the siphon position (extended or not) and feeding activity (pumping or not) of each clam prior to introduction of the predator treatments and at $4 \mathrm{~min}$ intervals after introduction for $20 \mathrm{~min}$. Thus, each clam could have been observed feeding (pumping) a maximum of 6 times, and we used the number of observations in which clams were pumping as a measure of clam pumping time. We tested clam responses to a variety of sympatric predators including American lobsters, rock crabs, Jonah crabs, green crabs, and northern starfish as well as injured conspecifics. We also exposed clams in Maine to knobbed whelks and blue crabs from Georgia, since Georgia clams react strongly to these predators (Smee \& Weissburg 2006a,b).

Results from initial experiments indicated that clams did not react to rock crabs, Jonah crabs, or green crabs, so we examined the responses of clams when rock crabs, Jonah crabs, and green crabs were allowed to actively consume clams during the behavioral trials. In these tests, we placed a single clam (0.03 to $0.04 \mathrm{~m}$ shell length) into the Vexar cage along with a caged crab. We removed the top valve of the clam so that each crab could readily consume the clam during the experiment. Clams reduced their feeding time when rock crabs were feeding on clams during these assays, but we did not detect a significant response by clams when Jonah crabs or green crabs were eating clams during the experiments (see 'Results'). These observations suggested that the crab's feeding manner exerted a significant effect. Rock crabs are messy eaters, and clam fluids and flesh pieces could be seen easily in the surrounding water as rock crabs ate clams in the flume. In contrast, we did not observe clam fluids being released when clams were consumed by Jonah crabs or green crabs. This suggested that the amount of clam fluid (degree of clam injury) being released might influence clam reactions, and we conducted 2 final experiments to examine this supposition.

We investigated how the amount of clam fluid released by crabs during feeding affected clam reactions by removing the top valve of a clam and making a single laceration to its visceral mass using a knife. We then placed a caged rock crab upstream from the clams as before and placed the injured clam outside the cage so that the crab could not consume the clam. This allowed the clams to receive odors from an injured clam and a rock crab simultaneously, even though the crab was not feeding. Clam fluids were not visible during this trial, and thus, the quantity of injured clam cue more closely represented that ob- 
served in trials when Jonah or green crabs were feeding. In the second experiment, we placed only an injured clam upstream from the experimental clams. In this trial, we made multiple lacerations on the visceral mass of the clam with a knife immediately before placing it into the flume and again after it had been in the flume for $10 \mathrm{~min}$. Fluids could easily be seen leaking into the flume with this level of clam injury, and appeared qualitatively similar to metabolite release produced by feeding rock crabs.

The order of treatments and controls in these experiments was randomly assigned each day, and each treatment and the control were replicated at least 5 times $(5$ trials $\times 3$ clams per trial $=15$ clams for each treatment and control). Additional control trials were conducted each day to establish a baseline of clam pumping in the absence of predators. Each clam and predator were used only once and then returned to the field. Approximately $20 \%$ of the clams were excluded from analysis because they neither pumped nor burrowed.

Smee \& Weissburg (2006a,b) found in a similar flume study that neighboring clams behave independently of one another, and thus, we assumed interactions between clams were not biasing our results. Since clams do not influence each other, the behavior of a single clam is an appropriate unit of measurement. Observations of pumping behavior of individual clams (number of siphon extensions observed for each clam) were arcsine transformed to meet ANOVA assumptions and then compared using a nested ANOVA that examined the effects of predator treatment and trial nested within treatment (Sokal \& Rohlf 1995). Using a nested ANOVA allowed us to determine whether variations in clam responses were affected by variability in cue quality or quantity across replicate treatments, which is a source of uncontrolled variation in our experiments. The $\mathrm{p}$-value for the nested effect was greater than 0.25 in all experiments, indicating that clams in different groups did not display significantly different responses to the same treatments, and suggests that cues from predators and injured conspecifics were roughly similar between replicate trials. Nest effects have not been found in other studies using similar assays, (Smee \&Weissburg 2006a,b).

The lack of a significant nesting effect permitted us to lump trials within treatments and test the significance of the main effect using the pooled error variance (Sokal \& Rohlf 1995). A Tukey-Kramer post hoc analysis was employed to test for pair-wise differences between treatments and controls (Sokal \& Rohlf 1995). We employed 3 separate ANOVAs to examine changes in clam behavior caused by risk because clams react to predators by either withdrawing their siphons (i.e. shell closure) or by ceasing to feed but leaving their siphons extended (i.e. pumping cessation). In the first ANOVA, we compared the number of clam reactions between treatments and controls by combining responses of shell closure with responses of pumping cessation. We performed 2 additional ANOVAs in which we looked separately at each clam response to predators (siphon withdrawal and pumping cessation with siphons extended). These additional tests allowed us to compare the types of responses clams displayed with each treatment. We deemed pumping cessation as a less intense reaction to risk than was siphon withdrawal, and examining these behaviors separately allowed us to determine the level of response of Maine clams to each treatment. We also performed power analysis on these treatments to verify that our statistical power was sufficient to detect differences between treatments (Sokal \& Rohlf 1995).

Comparing clam reactions from Georgia and Maine: Environmental conditions, most notably temperature, vary greatly between Georgia and Maine. We conducted 2 additional experiments in the summer of 2007 to determine whether differences in water temperature were affecting our results. Hard clams were collected in Georgia and shipped to Maine where we investigated the reactions of Georgia clams to predation risk in the flume at the DMC using the aforementioned methodology.

Previously, Smee \& Weissburg $(2006 \mathrm{a}, \mathrm{b})$ noted that clams in Georgia significantly reduced their pumping time in the presence of blue crabs, knobbed whelks and injured conspecifics. These experiments were performed in water temperatures that exceeded $20^{\circ} \mathrm{C}$ at the Skidaway Institute of Oceanography near Savannah. We were able to examine any effects of temperature on the reactions of Georgia clams to risk cures by repeating some of these experiments in the cold water $\left(10^{\circ} \mathrm{C}\right)$ in the DMC flume. As before, knobbed whelks and blue crabs were collected in Georgia and shipped to the DMC in Maine, and all exotic animals were housed and carefully quarantined to ensure that nonnative organisms were not released into Maine waters. We exposed Georgia clams to knobbed whelks, blue crabs and injured conspecifics, as well as to rock crabs locally collected in Maine. These risk treatments were selected because reactions of Georgia clams to knobbed whelks, blue crabs and injured conspecifics had previously been examined in warm water (Smee \& Weissburg 2006a,b). We also examined Georgia clam responses to rock crabs as these predators are common in Maine, but do not elicit reactions from Maine clams.

As before, we employed 3 separate ANOVAs to examine changes in clam behavior in response to risk (Sokal \& Rohlf 1995). In the first ANOVA, we compared the number of clam reactions between treatments and controls by combining responses of shell 
closure with responses of pumping cessation (with shells open and siphons extended). We performed 2 additional ANOVAs in which we looked separately at each clam response to predators (siphon withdrawal versus pumping cessation with siphons extended) (Sokal \& Rohlf 1995).

We conducted a final experiment during the summer of 2007 to directly compare responses of Georgia and Maine clams to similar risk levels. In this experiment, we conducted behavioral assays as previously described using the scent of injured clams as our risk cue. The risk cue was created by selecting a clam that was 0.033 to $0.037 \mathrm{~m}$ in size, removing its top valve and making a single laceration on its visceral mass with a knife. We exposed 30 clams from both Georgia and Maine (10 groups of 3 each from each location) to this risk level alternatively in the DMC flume and compared reactions of clams from Georgia to clams from Maine using 3 nested ANOVAs. The nested ANOVAs did not reveal significant nest effects, and we used $t$ tests to examine the number of times clams withdrew their siphons, ceased pumping without withdrawing their siphons, and the total number of reactions to cues from injured conspecifics (Sokal \& Rohlf 1995). Unlike earlier experiments where clams were used within $48 \mathrm{~h}$ of collection, we housed both Maine and Georgia clams in isolated aquaria for $1 \mathrm{wk}$ prior to use in these experiments. This time was necessary to allow Georgia clams to acclimate to the colder temperatures after shipment (and remain quarantined) and allowed us to house both Georgia and Maine clams in similar conditions prior to use in this comparative assay. We also performed control trials in which we examined the number of pumping cessations for both Maine and Georgia clams without upstream predators and injured clams. Control trials were performed before and after the previously described assays examining Georgia versus Maine clam reactions to injured conspecifics.

\section{RESULTS}

\section{Density survey}

Clam densities were significantly higher in Georgia than in Maine (Fig. 1, $t=7.79, \mathrm{n}=50, \mathrm{p}<0.001$ ), with densities measuring $26.1 \pm 1.5$ (mean $\pm \mathrm{SE}$ ) and $9.1 \pm$ 1.2 clams $\mathrm{m}^{-2}$ respectively. In Maine, 35 of 50 clam beds had $<10$ clams $\mathrm{m}^{-2}$, and only 4 had $\geq 20$ clams $\mathrm{m}^{-2}$. In comparison, 36 clam beds in Georgia had densities $>20$ clams $\mathrm{m}^{-2}$, and only 2 had densities $<10$ clams $\mathrm{m}^{-2}$. The sizes of clams collected were noticeably different between these areas, as juveniles were rarely collected in Georgia, but accounted for nearly $30 \%$ of total clam collections in Maine (Fig. 1).

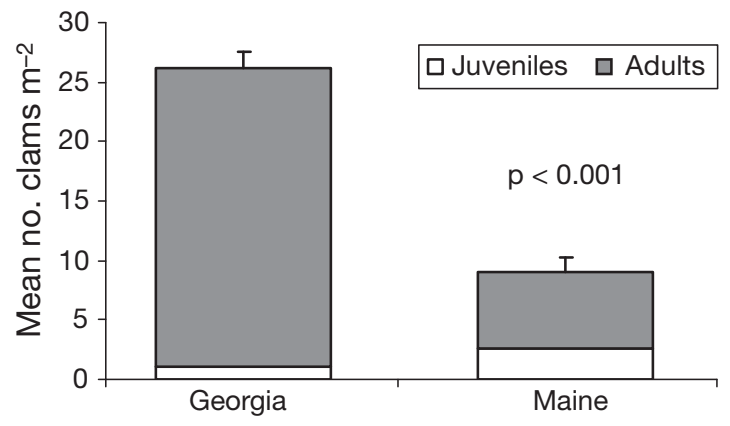

Fig. 1. Mean density $(+\mathrm{SE})$ of clams per $\mathrm{m}^{-2}(\mathrm{n}=50$ plots per site) in Georgia and Maine. Mean density of juvenile and adult clams collected in each area are also shown. Clam densities between these areas were significantly different $(\mathrm{p}<0.001)$

\section{Predation intensity}

Predation intensity on clams in Maine versus Georgia was compared using clam plots with 15 clams per $0.25 \mathrm{~m}^{2}$. The rate of clam predation was significantly higher in Georgia compared with that in Maine (Fig. 2, $t=8.1, \mathrm{n}=20, \mathrm{p}<0.001$ ), and the total number of clams eaten in Georgia was much higher than in Maine even though plots in Maine were in the field for $1 \mathrm{wk}$ and those in Georgia were recovered after $48 \mathrm{~h}$. On average, 0.3 clams were eaten per day in Maine compared with 2.7 clams d $^{-1}$ in Georgia. Despite the additional time in the field and artificially high clam density in Maine, the mean number of clams consumed per plot in Georgia was still more than twice that measured in Maine. An initial study in both locations revealed that predation was nearly nonexistent in Maine within $48 \mathrm{~h}$, but $>95 \%$ of clams were consumed in Georgia after 1 wk. Roughly $90 \%$ of clam mortality was attributed to crustaceans in both Georgia and Maine, and juvenile clams were more commonly eaten than adults (Fig. 2).

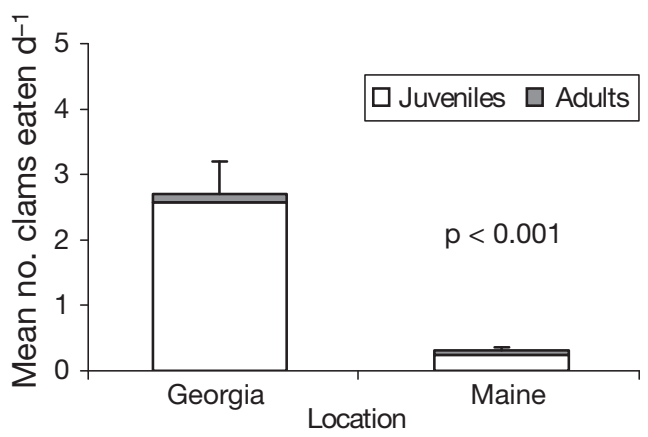

Fig. 2. Mean number (+SE) of adult and juvenile clams consumed per day in the field plots in Georgia and Maine. Twenty clam plots were placed in both Georgia and Maine, and predation rates were significantly different $(p<0.001)$. Nearly $100 \%$ of juvenile clam mortality was attributed to crustacean predators 


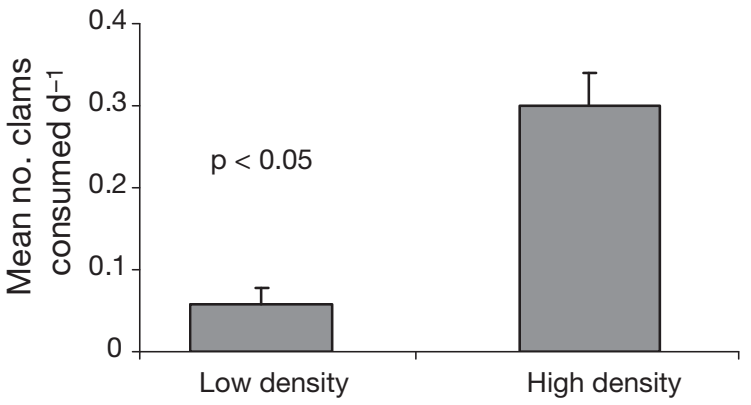

Fig. 3. Mean number of clams consumed per day $(+\mathrm{SE})$ in low and high density plots in Maine. Plots ( $\mathrm{n}=10$ pairs) remained in the field in Maine for $1 \mathrm{wk}$. Low density plots contained 5 clams and high density plots contained 15 clams per $0.25 \mathrm{~m}^{2}$. High density plots had significantly higher predation rates $(\mathrm{p}<0.05)$ than low density plots

Clam plots in Maine had a significantly higher density than naturally occurring clam beds, which may have artificially elevated measured predation rates. Thus, we performed another experiment to explicitly compare clam predation in Maine in low $(5$ clams per $0.25 \mathrm{~m}^{2}$ ) and high (15 clams per $0.25 \mathrm{~m}^{2}$ ) density plots. The low density plots more closely resembled the naturally occurring density of Maine clams, whereas the high density plot reflected naturally occurring densities in Georgia. The high density plot in these experiments (Fig. 3) experienced similar mortality as that occurring in the initial experiments comparing predation in Georgia versus Maine (Fig. 2). Significantly more clams were consumed in the higher density plots when compared with the low density plots (Fig. $3, t=$ $4.02, \mathrm{n}=20, \mathrm{p}<0.05$ ). Eight of the 10 low density plots were recovered with $100 \%$ of the clams alive, whereas only 2 of the 10 high density plots displayed zero mortality. Thus, the high density plots were 4 times more likely to be discovered by predators, suggesting that Maine clams may gain a spatial refuge from predators by existing in low densities.

\section{Behavioral assays}

Smee \& Weissburg $(2006 a, b)$ found that clams in Georgia respond to predation risk (i.e. predator cues) by withdrawing their siphons and closing their shells (siphon withdrawal). We found that clams in Maine showed 2 different responses to risk. Clams sometimes would cease pumping by closing their excurrent siphon, but would leave their siphons extended and shells open (pumping cessation). In other cases, clams would withdraw their siphons and close their shells. Thus, we documented occurrences of both siphon withdrawal and pumping cessation for clams in Maine.
In the DMC flume, we examined changes in clam behavior caused by the presence of sympatric and exotic predators, injured conspecifics and combinations of these cues. The first analysis compared all changes in clam pumping behavior caused by predators (siphon withdrawal plus pumping cessation), and we found that clams reduced their pumping time by $40 \%$ to $75 \%$ after detecting starfish, rock crabs eating clams, injured (lacerated) clams, blue crabs and knobbed whelks (Fig. 4, $F_{12,209}=6.2, \mathrm{p}<0.01$, power level $\left.=1.0\right)$. The second analysis indicated that a significant siphon withdrawal
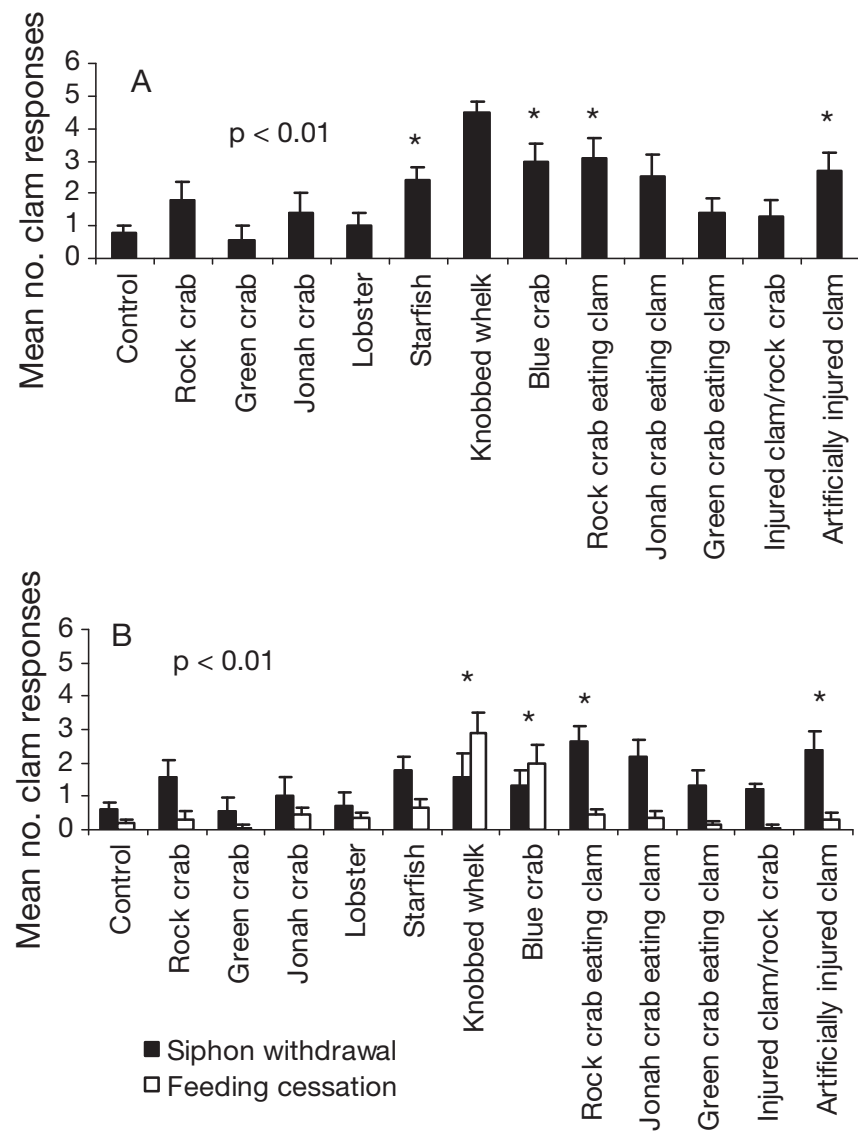

Fig. 4. Mean number $(+\mathrm{SE})$ of responses of Maine clams exposed to all treatments in the flume behavioral assays. Responses range from 0 (clams observed pumping in all 6 observations) to 6 (clam reacted in all 6 observations). (A) Total number of clam responses. (B) Number of each type of response (siphon withdrawal and feeding cessation) separately. Asterisks (*) denote means significantly different from the control based on a Tukey-Kramer post hoc test. Treatments marked rock, Jonah or green crabs eating clams are trials in which the crab was consuming a clam during the trial. The treatment marked injured clam/rock crab was performed with both an injured clam and a rock crab, but the crab was not allowed to contact the clam, and the clam was punctured only once. The artificially injured clam was lacerated with a knife multiple times to mimic rock crab feeding. Sample sizes (listed in the same order as in the figure from left [control] to right) are $\mathrm{n}=44,14,13,11,15,16,14,13,16,13,14,14$ and 15 
response occurred for clams exposed to rock crabs eating clams and to the severely injured clams wounded with a knife (Fig. 4, $F_{12,209}=2.54, \mathrm{p}<0.01$, power level $=$ 0.99). The final ANOVA revealed that clams responded to exotic blue crab and knobbed whelk predators with pumping cessations but without siphon withdrawal (Fig. 4, $F_{12,209}=6.04, \mathrm{p}<0.01$, power level $=0.88$ ). The clam reactions to starfish were not significantly different than controls when we examined each response component (withdrawal and pumping cessation) separately. Clams exposed to starfish would display both responses and would sometimes close, whereas other times they would stop pumping but leave their siphons extended. Thus, there was a significant behavioral change in this treatment, but examining these behaviors separately does not reveal that either occurred at a level significantly different than the control.

Clam pumping was not significantly affected by lobsters, rock crabs, green crabs and Jonah crabs, even when green and Jonah crabs were feeding on clams during the assays. Clams also reacted to the artificially injured clams that we pierced repeatedly with a knife until clam fluids were leaking into the water, but they did not respond to the clam injured with a single wound and placed in the flume next to a rock crab. Qualitative observations revealed that rock crabs were extremely aggressive eaters, piercing clams with their claws and releasing clam fluids into the water, whereas green and Jonah crabs primarily consumed the clam using only their mouthparts, and clam fluids released into the water were not visible. These observations suggest that fluids from injured clams are the cue responsible for clam responses seen when rock crabs consume clams.

In summary, Maine clams reduced their pumping time after detecting starfish, blue crabs and knobbed whelks, but did not withdraw their siphons in response to these predators. Maine clams did withdraw their siphons after detecting rock crabs eating clams and artificially injured clams, but showed no response to lobsters, rock crabs, green crabs or Jonah crabs, even when the latter 2 crab predators were feeding on clams.

\section{Assays with Maine and Georgia clams}

Clams from Georgia that were shipped to Maine and assayed in the DMC flume displayed significant reactions to sympatric blue crab and knobbed whelk predators as well as to rock crabs, which are not found in Georgia. Georgia clams altered their feeding behavior in predator treatments significantly more than in controls both by withdrawing their siphons (Fig. 5, $F_{3.45}=$ $5.7, \mathrm{p}<0.01$, power level $=0.85)$ and by ceasing to feed with siphons extended (Fig. 5, $F_{3.45}=5.5$, p $<0.01$, power level $=0.83$ ). Analysis of combined reactions also

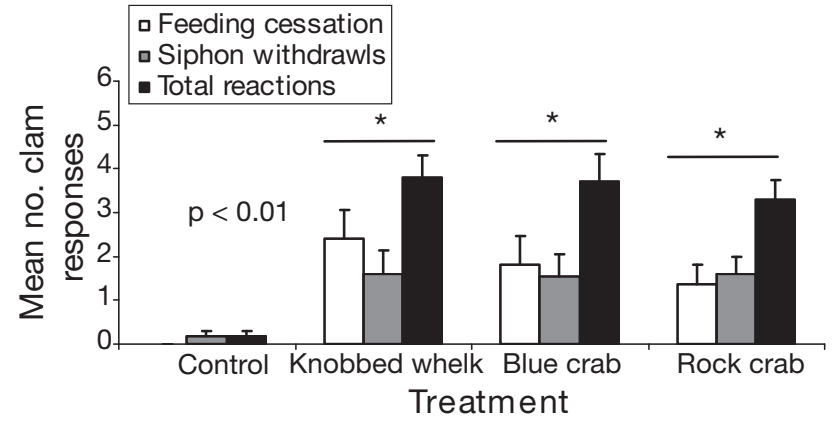

Fig. 5. Mean number $(+\mathrm{SE})$ of responses of Georgia clams in the DMC flume. Responses range from 0 (clams observed pumping in all 6 observations) to 6 (clams reacted in all 6 observations). Bars are indicative of the type of response. Sample sizes (listed in the same order as in the figure from left [control] to right) are $\mathrm{n}=18,9,11$ and 10. Asterisks ( ${ }^{*}$ ) denote means significantly different from the control based on a Tukey-Kramer post hoc test, and horizontal lines indicate that all response measurements were significantly different from controls

revealed a significant response between treatments and controls for Georgia clams (Fig. 5, $F_{3.45}=23.2$, p < 0.001 , power level $=1.0$ ). Post hoc analysis did not detect a significant difference in Georgia clam reactions to their native predators and to an exotic predator (rock crab) from Maine (Fig. 5), but did show that all predator treatments caused significant reactions compared with controls. Furthermore, Georgia clams reacted to these predator treatments by withdrawing their siphons and ceasing to feed with their siphons extended. Clams from Maine did not respond to rock crabs (even though this is a native and common predator) and only responded to blue crabs and knobbed whelks by feeding cessation and not by siphon withdrawal.

The frequency and types of responses to risk were directly compared between Georgia and Maine clams when exposed to similar risk levels using cues from injured conspecifics. We found that total responses to this treatment (combined instances of siphon withdrawal and pumping cessation without withdrawal) were significantly different between clams collected from Georgia and Maine (Fig. 6, $t=2.67, \mathrm{n}=54, \mathrm{p}<$ 0.01 ) as were instances of siphon withdrawal (Fig. 6, $t=$ 2.06, $\mathrm{n}=54, \mathrm{p}<0.05)$. Despite a strong trend, we did not observe a significant difference between Georgia and Maine clams in the number of times they ceased pumping but without withdrawing their siphons (Fig. 3, $t=1.77, \mathrm{n}=54, \mathrm{p}=0.082$ ). Differences in response intensity to chemical cues do not seem to reflect general behavioral differences between these 2 populations, but rather specific differences in response to risk. In the absence of risk, pumping activity was nearly identical for Georgia and Maine clams as they were observed to cease pumping in control trials $0.17 \pm$ 0.51 and $0.3 \pm 0.95$ times, respectively $(\mathrm{N}=18)$. 


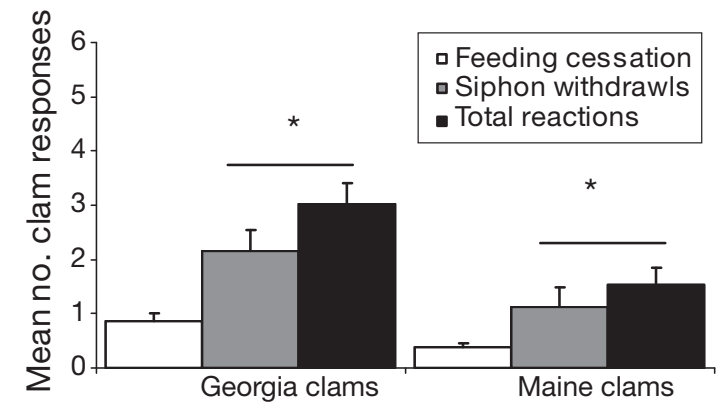

Fig. 6. Mean number (+SE) of responses of Georgia and Maine clams in the DMC flume when exposed to odors from injured conspecifics. Responses range from 0 (clams observed pumping in all 6 observations) to 6 (clams reacted in all 6 observations). Bars are indicative of the type of response. Twenty-seven clams from each population were compared. Note that total reactions to predators and instances of siphon withdrawal were significantly different $(\mathrm{p}<0.01$ and 0.05 , respectively), but pumping cessation with siphons extended was not $(\mathrm{p}=0.082)$. Asterisks $(*)$ denote significantly different means, and horizontal lines indicate that siphon withdrawals and total reactions were significantly different

\section{DISCUSSION}

Prey use many tactics to minimize their susceptibility to consumers including changing their morphology (Vermeij 1978, Leonard et al. 1999, Nakaoka 2000), increasing their levels of chemical defenses (Bolser \& Hay 1996, Pennings et al. 2001) and altering their behavior or habitat selection (Bertness et al. 1981, Fawcett 1984, Turner \& Mittlebach 1990). Our results suggest that, like other defensive adaptations, predator perception and the likelihood of initiating predator avoidance behaviors are related to local predation pressure. Clams from Maine (low predation) respond to few predators, respond frequently with intermediate behaviors (feeding cessation) even to predators that evoke dramatic responses from Georgia clams, and require cues indicative of an immediate potential threat (cues from injured conspecifics) before initiating their most protective behavior (shell closure). Most notably, clams from Georgia, where clam predation pressure was high, displayed a significantly greater reaction to risk than conspecifics from Maine when exposed to the same levels of risk under common environmental conditions.

\section{Clam density and predation pressure}

We found that clam densities were 3-fold higher in Georgia than in Maine (Fig. 1), that juvenile clams were much less common in Georgia, and that predation on clams was significantly higher in Wassaw Sound, Georgia, than in the Damariscotta River, Maine
(Fig. 2). The higher level of clam predation measured in Georgia was especially striking considering that predation rates in Maine were probably elevated by placing clams in the field at unnaturally high densities (Fig. 3). The rate of clam predation per day was 9 times higher in Georgia (2.7 clams eaten per day versus 0.3 in Maine). We believe our field estimates are broadly representative of local patterns in predation intensity because our field sites were large, stretched for several kilometers and incorporated a variety of microhabitats common in each respective area. Moreover, we measured clam predation in locations with natural clam populations. Although ubiquitous in Georgia, hard clams are difficult to find in Maine. Our predation comparisons between sites are based upon samples from a variety of localized conditions within each habitat. Moreover, in Georgia, our results were similar to predation levels measured in adjacent estuaries (Smee 2006), suggesting that our estimates of clam predation are representative of numerous habitats in Georgia.

Crushed clam shells and missing clams are indicative of predation by crustaceans (Micheli 1997, Nakaoka 2000), and almost all clam mortality in our plots in both Georgia and Maine was caused by crustacean predators. Hard clams reach a size refuge from blue crab predators when their shells reach $30 \mathrm{~mm}$ across (Micheli 1995, 1997), and we found that juvenile clams were more readily eaten than were adults in both study sites. The fraction of mortality attributable to predation on juveniles was $95 \%$ and $80 \%$ in Georgia and Maine, respectively, and juvenile clams were rarely collected in Georgia, but were much more common in Maine (Fig. 1, the ratio of adults to juveniles in Georgia was 25:1 and in Maine was 3:1). Walker et al. (1980) monitored predation on clams in experimental field plots in Wassaw Sound and found that predation was much more common on juveniles than on adults and juvenile clams were rare in Wassaw Sound. Our results are consistent with these findings.

Hard clam growth rates are significantly faster in lower latitudes during their first year due to the warmer temperatures (Wilson et al. 2002). The faster growth rate, along with the higher predation rate on juveniles, are probably responsible for the lower abundance of juveniles seen in Georgia. Intense predation in Georgia removes many juveniles, and clams in Georgia grow through the juvenile stages more quickly. As seen in Georgia, predation on juvenile clams in Maine was more common than on adults, and while collecting animals using SCUBA, we noted that crabs were the most commonly observed predators (D. Smee pers. obs.). Crabs primarily consume juvenile clams (e.g. Micheli 1997, Nakaoka 2000). Thus, in Maine clams are in the juvenile stage, when they are more vulnerable to their most common predators, for greater periods of time 
than they are in Georgia. Despite the longer time spent at a more vulnerable size, Maine clams experience significantly less predation than do Georgia conspecifics.

Even with more intense predation (Fig. 2), clam densities were nearly 3-fold higher in Georgia than Maine (Fig. 1). The high clam density in Georgia, coupled with the heavy predation on juvenile clams, suggests that clams in this population experience a bottleneck caused by predation from crustaceans, ensuring that any surviving clams in this area possess keen predator avoidance capabilities. That is, predation pressure in Georgia has probably selected for heightened predator detection and avoidance responses whereas the low predation pressure in Maine has not. The greater sensitivity to predators may allow Georgia clams to reach high densities, despite the intense consumer pressure. In Maine, low clam density may result from any number of factors including low recruitment levels, slow growth and/or minimal reactions to predators. Regardless, our results indicate that predation levels increase with density, and by existing in lower densities, Maine clams gain a spatial refuge from predators. The spatial refuge then allows Maine clams to survive in low numbers despite the reluctance or inability to respond to predators.

\section{Risk responses of Georgia and Maine clams}

Clams in Georgia and Maine experienced vastly differently levels of predation pressure, and we were able to use these clam populations in natural experiments to test whether prey perception of and reaction to risk are heightened in habitats with intense consumer pressure. Previous research by Doering (1982), Irlandi \& Peterson (1991) and Smee \& Weissburg $(2006 a, b)$ found that hard clams reacted to predators by withdrawing their siphons and closing their shells. Clams that close their shells in response to risk reduce their growth rate and fecundity (Irlandi \& Peterson 1991, Nakaoka 2000) but improve their chances of survival (Smee \& Weissburg 2006a). This study is the first to document a reaction of hard clams to predators where they cease pumping but leave their siphons extended. The costs and benefits of this behavior are unknown, but clams probably remain vulnerable to consumers by not withdrawing their siphons (Burnett 1960). Thus, we interpreted this behavior as an intermediate response to risk and complete shell closure as a stronger reaction to predators. Predation pressure is high in clam populations in the south that have not been observed to employ this intermediate behavior. Clams from populations in North Carolina and Georgia close up completely after detecting predators or injured conspecifics (Irlandi \& Peterson 1991, Smee \& Weissburg 2006a,b). We did note, however, that some clams imported from Georgia also responded to risk by ceasing to pump without withdrawing into their shells (i.e. intermediate response). The intermediate responses observed in this study may represent a reaction to predators mediated by temperature. We speculate that the failure to close fully may be a strategy to minimize avoidance costs when temperatures are low and costs are greatest, or this reaction might occur as predators may also be less active in colder temperatures. More work is needed to address these issues, but regardless, Georgia clams were more inclined to display full shell closure than conspecifics from Maine when assayed using the same risk levels and in the same water temperatures. Maine clams may have been selected to use the intermediate predator response to deal with the colder temperatures, but again, more work is needed to addresses the costs and benefits of predator avoidance for clams in Maine.

Smee \& Weissburg $(2006 a, b)$ have shown that hard clams in Georgia reduce their feeding time by 40 to $50 \%$ and withdraw into their shells after detecting injured conspecifics as well as blue crab and knobbed whelk predators. Results from our behavioral assays indicated that Maine clams reduced their feeding time when exposed to starfish, but did not react to any other sympatric predators tested including lobsters, rock crabs, green crabs and Jonah crabs (Fig. 4). Interestingly, Maine clams did not react to any of their crustacean predators even though these consumers were responsible for the majority of clam mortality in our field experiment (Fig. 2). Although Maine clams did reduce their feeding time in the presence of starfish, they did not withdraw their siphons into their shells in some of the assays. The response to starfish in this study differed from that of conspecifics farther south where predation is more intense (Doering 1982). Doering (1982) noted that hard clams from Rhode Island withdrew into their shells when placed downstream from starfish, and they did not display intermediate risk responses.

Reactions of Maine clams to their sympatric predators were generally much less intense than reactions of Georgia clams to their local primary consumers, as judged by the frequency of total events, cessations and withdrawals. We exposed clams in Maine to Georgia clam predators, which allowed us to compare clam responses to the same predators from 2 distinct populations that experienced vastly different levels of consumer pressure. Maine clams responded to knobbed whelks and blue crabs by reducing their feeding time but not closing their shells (Fig. 4). Thus, clams in Maine reacted less intensely than did Georgia clams to the same predator signals (Figs. 4 \& 5). We were somewhat surprised that Maine clams reacted to these exotic predators, especially since they did not react to local crustacean consumers, and we offer possible explanations for these results. First, 
blue crabs and knobbed whelks may exude larger quantities of metabolites than Maine crustaceans and are, thus, easier for clams to detect. This explanation may also account for the response of Maine clams to starfish, if starfish are releasing larger quantities of warning cues than are crustaceans. Second, Maine clams reacted to blue crabs and knobbed whelks as they did to starfish (by not feeding but leaving their siphons extended), so the chemical signature of these exotic predators may be similar to starfish. Finally, Maine clams may be descendents from clam populations farther south where blue crabs and knobbed whelks commonly occur. Although we are uncertain of the mechanisms that allow Maine clams to detect knobbed whelks and blue crabs, it is clear that clams in Maine do not respond to blue crabs and knobbed whelks as strongly as do Georgia clams (Figs. 4 \& 5).

We observed the most intense reactions of Maine clams when they were presented with odors from conspecifics that were being consumed by rock crabs or that had been repeatedly injured. These treatments were the only ones in which we observed Maine clams withdrawing into their shells. Metabolites leaking from injured clams thus are both necessary and sufficient to evoke shell closure. Clams closed their shells in response to rock crabs that were consuming clams, did not respond when exposed to a clam with a single puncture wound alongside a caged rock crab, but did withdraw into their shells when exposed to a conspecific that was repeatedly lacerated before and during the experiment. Maine clams did not react as strongly as did Georgia clams to conspecifics with a single puncture wound (Fig. 6), suggesting that Maine clams primarily use cues from injured conspecifics to evaluate risk, but require a higher level of cue before predator avoidance behaviors are initiated than do clams from Georgia. We did not observe any clam reactions from Maine clams when Jonah or green crabs were eating clams during the experiments. These responses may be explained by the crab's feeding manner. Rock crabs are messy eaters, and clam fluids and flesh pieces could be easily seen during feeding as rock crabs ate clams in the flume.

\section{Environmental differences versus predation pressure}

Clams in Maine were less responsive to local predators, reacted less strongly to knobbed whelks and blue crabs, and required a higher level of injured clam signal than Georgia conspecifics before reacting to risk. Combined with our data showing the significantly greater level of predation pressure in Georgia, these results suggest that clam sensitivity to cues indicative of predation risk is related to predation intensity. Two possible mechanisms may explain this phenomenon.
First, intense predation pressure has selected for heightened sensitivity in clam populations in Georgia, creating a bottleneck that ensures that clams reaching adulthood are capable of reacting to consumers. Although crustacean predators accounted for the majority of clam mortality in Maine, the consumer pressure there was insufficient to select for heightened predator detection and avoidance capabilities.

Alternatively, differences in environmental conditions (e.g. temperature, food availability, habitat type) affect the costs of shell closure, and Maine clams continue to pump in the presence of predators to meet basic energetic requirements. In this situation, low predation pressure in Maine enables clams to survive without reacting to predators, but in Georgia, intense predation pressure eliminates clams that fail to respond to predatory threats. Furthermore, a weaker response by Maine clams may have been selected for if these clams indeed pay a higher cost for closing their shells. Regardless of the mechanism, predators play a key role in modulating the evolution of clam behavior as low predation in Maine would allow clams with weaker responses to predators to survive while in Georgia these clams would most certainly be consumed.

Smee \& Weissburg (2006a) demonstrated that clam survival increased when clams reacted to predators, and thus, costs incurred by clams are not unrewarded. Even if there is a greater cost associated with predator avoidance in Maine, the costs of failure to avoid predators is probably still less than the alternative (death), suggesting that cost differences are inadequate to account for differential responses from clams in these populations. Finally and most notably, Georgia clams reacted more strongly to predators and predation risk than did clams from Maine when assayed in the same flume with untreated seawater imported directly from the Damariscotta River (water temperature $\sim 10^{\circ} \mathrm{C}$ ), suggesting that environmental differences alone cannot account for differences in predation responses between Georgia and Maine clams.

\section{Biogeographical effect or localized pattern}

In our study, we found that Maine clams reacted less intensely to predation risk than did conspecifics from Georgia (Figs. 4 to 6, Smee \& Weissburg 2006a,b), and to previously reported responses of clams to predators in North Carolina (Irlandi \& Peterson 1991) and Rhode Island (Doering 1982). Our results, along with those of Bertness et al. (1981) and Fawcett (1984), indicate that predator avoidance behaviors differ between populations that experience different levels of consumer pressure. Consumer pressure is generally greater in lower latitudes (Vermeij 1978, Jeanne 1979, Bertness et al. 
1981, Menge \& Lubchenco 1981, Gaines \& Lubchenco 1982, Fawcett 1984, Heck \& Wilson 1987, Bolser \& Hay 1996, Pennings et al. 2001) and our results, along with those of Doering (1982) and Irlandi \& Peterson (1991), suggest that heightened predator awareness may exhibit a biogeographical pattern, like other prey responses to consumers (Vermeij 1978, Bertness et al. 1981, Bolser \& Hay 1996, Pennings et al. 2001). However, predation rates on hard clams can vary dramatically within localized habitats (e.g. Micheli 1997, Nakaoka 2000), and additional clam populations must be sampled to determine whether this is a robust biogeographical pattern or our results stem from local variation in predation pressure.

Acknowledgements. We thank P. Jumars for allowing us to use his flume for the behavioral experiments, D. Burnham, M. Ferner, M. Watts, J. Hill, S. Large, C. Rigaud and the personnel in R. Wahle's lab for assistance in collecting animals, and T. Miller for logistical support at the Darling Marine Center. Funding support for this project came from the NSF IGERT grant to the Georgia Institute of Technology, NSF-OCE grants to M.J.W. (no. 0424673), G. Trussell (no. 0648525), and D.L.S. (no. 0648433) and from the Texas Research Development Fund and TAMUCC startup funds to D.L.S.

\section{LITERATURE CITED}

Bertness MD, Garrity SD, Levings SC (1981) Predation pressure and gastropod foraging: a tropical-temperate comparison. Evolution 35:995-1007

Bolser RC, Hay ME (1996) Are tropical plants better defended? Palatability and defenses of temperate and tropical seaweeds. Ecology 77:2269-2286

Burnett AL (1960) The mechanism employed by the starfish, Asterias forbesi, to gain access to the interior of the bivalve, Venus mercenaria. Ecology 41:583-584

Coley PD, Aide TM (1991) Comparison of herbivory and plant defenses in temperate and tropical broad-leaved forests. In: Price PW, Lewinsotin TM, Fernandes GW, Benson WW (eds) Plant-animal interactions: evolutionary ecology in tropical and temperate regions. Wiley, New York, p 25-49

$>$ Doering PH (1982) Reduction of attractiveness to the sea star Asterias forbesi (Desor) by the clam Mercenaria mercenaria (Linnaeus). J Exp Mar Biol Ecol 60:47-61

Fawcett MH (1984) Local and latitudinal variation in predation on an herbivorous marine snail. Ecology 65: $1214-1230$

Gaines SD, Lubchenco L (1982) A unified approach to marine plant-herbivore interactions. II. Biogeography. Annu Rev Ecol Syst 13:111-138

Harvell CD (1986) The ecology and evolution of inducible defenses in a marine bryozoan-cues, costs, and consequences. Am Nat 128:810-823

Hay ME (1996) Marine chemical ecology: What is known and what is next? J Exp Mar Biol Ecol 200:103-134

Heck KL Jr, Wilson KA (1987) Predation rates on decapod crustaceans in latitudinally separated seagrass communities: a study of spatial and temporal variation using tethering techniques. J Exp Mar Biol Ecol 107:87-100

Irlandi EA, Peterson CH (1991) Modification of animal habitat by large plants: mechanisms by which seagrasses influence clam growth. Oecologia 87:307-318
Jeanne RL (1979) A latitudinal gradient in rates of ant predation. Ecology 60:1211-1224

Katz LB, Dill LM (1998) The scent of death: chemosensory assessment of predation risk by animals. Ecoscience 5: 361-394

Leonard GH, Bertness MD, Yund PO (1999) Crab predation, waterborne cues, and inducible defenses in blue mussels, Mytilus edulis. Ecology 80:1-14

Lima SL, Dill LM (1990) Behavioral decisions made under the risk of predation: a review and prospectus. Can J Zool 68: $619-640$

Menge BA, Lubchenco J (1981) Community organization in temperate and tropical rocky intertidal habitats: prey refuges in relation to consumer pressure gradients. Ecol Monogr 51:429-450

Micheli F (1995) Behavioural plasticity in prey-size selectivity of the blue crab Callinectes sapidus feeding on bivalve prey. J Anim Ecol 64:63-74

Micheli F (1997) Effects of predator foraging behavior on patterns of prey mortality in marine soft bottoms. Ecol Monogr 67:203-224

Nakaoka M (2000) Nonlethal effects of predators on prey populations: predator-mediated change in bivalve growth. Ecology 81:1031-1045

Pennings SC, Siska EL, Bertness MD (2001) Latitudinal differences in plant palatability in Atlantic Coast marshes. Ecology 82:1344-1359

Relyea RA (2001) Morphological and behavioral plasticity of larval anurans in response to different predators. Ecology 82:523-540

Schmitz OJ, Beckerman AP, O'Brien KM (1997) Behaviorallymediated trophic cascades: effects of predation risk on food web interactions. Ecology 78:1388-1399

Smee DL (2006) The ecology of yikes: environmental forces affect prey perception of predators. PhD dissertation, Georgia Institute of Technology, Atlanta

Smee DL, Weissburg MJ (2006a) Clamming up: physical forces diminish the perceptive ability of bivalve prey. Ecology 87:1587-1598

Smee DL, Weissburg MJ (2006b) Hard clams Mercenaria mercenaria evaluate predation risk using chemical signals from predators and injured conspecifics. J Chem Ecol 32: 605-619

Sokal RR, Rohlf FJ (1995) Biometry: the principles and practice of statistics in biological research, 3rd edn. W. H. Freeman, New York

Tollrian RI, Harvell CD (1999) The ecology and evolution of inducible defenses. Princeton University Press, Princeton, NJ

> Trussell GC, Ewanchuk PJ, Bertness MD (2003) Trait-mediated effects in rocky intertidal food chains: predator risk cues alter prey feeding rates. Ecology 84:629-640

Turner AM, Mittlebach GG (1990) Predator avoidance and community structure: interactions among piscivores, planktivores, and plankton. Ecology 71:2241-2254

Vermeij GJ (1978) Biogeography and adaptation. Harvard University Press, Cambridge, MA

Walker RL (1987) Hard clam, Mercenaria mercenaria (L.) populations of coastal Georgia. Georgia Mar Sci Cent Tech Rep Ser 87-1, Athens, GA

Walker RL, Fleetwoord MA, Tenore KR (1980) The distribution of the hard clam Mercenaria mercenaria (Linne) and clam predators in Wassaw Sound, Georgia. Georgia Mar Sci Cent Tech Rep Ser, Athens, GA

Wilson DM, Heck KL Jr, Coen LD (2002) Growth of northern [Mercenaria mercenaria (L.)] and southern [M. campechiensis (Gmelin)] quahogs: influence of seagrasses and latitude. J Shellfish Res 21:635-642

Submitted: June 6, 2006; Accepted: December 14, 2007

Proofs received from author(s): June 19, 2008 